\title{
Exploring the Practical Teaching Plan of C Language Programming
}

\author{
Bigeng Zhenga , Peng Deng \\ School of Electronics and Information Engineering, Jingchu University of Technology, Jingmen 448000, \\ China \\ ảBeginz@jcut.edu.cn
}

Keywords: teaching practice, C language, program design

\begin{abstract}
This paper discusses the application of undergraduate $C$ programming language teaching practice, according to the requirements of applied undergraduate education training, reasonable positioning of courses, adopting "step-style" and "case-style" classroom teaching methods, Teaching as the core, while building a variety of independent learning platform, using a more scientific and comprehensive assessment methods, better taking into account the different needs of students and stimulate students' enthusiasm for learning. "C Programming Language" is the first professional basic course that many professional colleges and universities in the field of information science, such as computer, electronics, communications and other professional students in contact with the door after the cross-national university, it is to develop students good programming skills and strong interest in computer science, as well as the follow-up professional knowledge of students play an important basis. Applied undergraduate personnel training is to follow the undergraduate talents to develop their own educational laws, while highlighting the practice, to strengthen the application of a talent education and training mode. In-depth study and discussion of applied undergraduate training mode program design teaching new mode and new method, obviously has important practical significance.
\end{abstract}

\section{Introduction}

As students enter the university after the first access to computer basic courses, programming courses should be positioned to enable students to have a preliminary programming ideas, have a certain degree of programming skills, familiar with the machine debugging procedures approach to develop a good programming Habit, design specifications and style, alone to solve the difficulties in programming and debugging, at the same time have the ability to communicate, express and cooperate with others.

\section{Course Goals}

Computer science education is a systematic project with continuity and integrity. Many courses such as programming, data structure, operating system, compilation principle and software engineering are all interrelated. As the cornerstone of this teaching system - programming courses, because most of the students to enter the university after learning the first program design courses, many students are less logical thinking ability, the narrative space is narrow, so it is not appropriate to set goals Too high. According to the differences of students 'basic and receptive ability, it is more practical to classify the teaching objectives according to the levels of students' learning. For example, for outstanding students, it is required to successfully meet the teaching requirements, to complete a more difficult comprehensive programming, and to give other students help, and to apply some of the knowledge learned to creatively solve some practical problems; for secondary students, Inspired to achieve the basic requirements of teaching, can independently complete the difficult exercises, can use the knowledge to solve a considerable degree of practical problems, to maintain the interest of programming and learning; for poor students, teachers and other students are required to be in With the help of the basic requirements of teaching to complete the basic exercises. Teaching goals also need teachers according to the individual differences in the students 
in the actual teaching process to make the appropriate adjustments to develop students' self-confidence and sense of accomplishment so that all kinds of students through their own efforts, and ultimately achieve their desired goals.

\section{Teaching Methods Reform}

The traditional teaching method focuses on explaining the basic grammar of $\mathrm{C}$ language. Most of the selected programming examples are used to verify and explain grammatical rules. This teaching method often allows students to learn C language, "see the trees out of the woods", indefinable, with no knowledge of language learning, debugging programs, often incorrect implementation of the results at a loss, at When developing integrated applications, software design skills are poor. In the application of undergraduate $C$ language programming courses in teaching, we have done a lot in teaching methods to improve, and achieved good teaching results.

\section{Teaching to Be used as the Principle}

C language knowledge more, covering a wide range of theoretical teaching time is relatively tight. After practice, from the application point of view dividing the content of knowledge, "to school", knowledge point to grasp the difficulty enough to use. At the same time, according to the characteristics and cognitive rules of beginners, disperse the difficulties and reduce the steps, grasp the key points in the example exercises, break through the difficulties, gradually penetrate the theoretical system in the curriculum, and explain the difficult contents in the chapters. For example, the contents of a function can be dispersed into chapters such as loops, arrays, pointers, files, and the like, and the pointers are merged together with the application of arrays, functions and files to make them easier to understand. This decomposition of many of the original point of view that there is difficulty of knowledge, so that students are not easy to produce fear of emotions, the students grasp the difficulties and priorities will gradually have a change from quantitative to qualitative change process.

\section{The Use of Pedagogy}

The teaching plan is designed to be stepped, so that students step up step by step, span is not large, in line with the law of learning. For example, in guiding students to achieve "Guess the number of games," the demand is set to ladder, divided into the use of a choice to achieve a judgment, the use of the cycle to achieve a guess, the use of multiple loops to achieve continuous guessing, and ultimately the game gradually improve the function of $\mathrm{j}$ one. The students gained a great deal of interest in this step-by-step pedagogy and were further enhanced by constant programming and debugging, tracking, programming skills and programming ideas. Classroom teaching focus on case analysis, student learning activities follow the case to imitate a problem summarizes a gradual expansion exercises step. For example, in explaining the function before the first case to explain the use of the function, first of all cause students interest in the use of the function, and then summarize the function call, statement, define, modify the program, so that students summarize some of the problems, and finally to further explain the custom Use of function Inspired by this case-based approach, students naturally, easily and thoroughly understand new knowledge and master the application of the function.

\section{Use Reflective Teaching Method}

Students gradually master and accumulate some common programming methods and techniques, you can think of reflection as an important teaching tool, a kind of "adhesive", the C programming language components or tasks stick to an organic overall. Teachers can often provide students some reflective mode, purposeful training, combined with the content of learning for sustained development. For example, when explaining N!, You can guide students to reflect algorithm 
characteristics of iterative method and recursive method step by step. When explaining the use of array of character pointers, students can be guided to reflect on using two-dimensional arrays to store strings and use them Pointer array string operations related to the relationship and differences.

\section{Project-driven Practical Teaching}

The German pedagogical assistant Duisheidi once said: "The art of teaching is not about imparting skills, but about motivation and calling." How to guide students' programming interest in practical teaching is one of the main purposes of practical teaching. The project-driven practical teaching selects the appropriate project according to the instructional setting and guides the students to realize the transformation from writing simple and simple programs to using practical linguistic programming to solve practical problems of certain difficulty. In practice teaching. The comprehensive project can be broken down into small programs that are constantly being practiced in all stages of learning. For example, the typical project of student performance management program is the core. By decomposing several modules of the project (data entry, modification, query and statistics) in different stages of learning and in different chapters.

The prototype of the textual menu (menu) Commonly used input / output statements print and scarE [begin to write; select the structure of the study can set the menu selection, loop, and the array can build class curriculum performance statistics; function learning to make small programs modular, and structure and community Learning can be used to store a large number of students' information; single-linked list learning can dynamically manage student achievement, and file operations can ultimately accomplish student achievement management. Finally, students examine the design of the whole program from a holistic point of view, and through comprehensive debugging on the machine, to achieve the purpose of improving the comprehensive programming ability. Project-based practical tasks are coherent, and there is always a task driven throughout the learning process of the subject. Driven by short-term tasks one after another, students experience the joy of success again and again to fully train students Analyze the problem and the ability to solve the problem, improve students' construction of programming meaning, and fully demonstrate the value orientation of "ability-based" in applied undergraduate teaching.

\section{Build a Variety of Independent Learning Platform}

Traditional inculcating teaching methods can not adapt to applied undergraduate education. Autonomous learning is a teaching design method based on the constructivist learning theory. The key to cultivating students 'self-regulated learning lies in cultivating students' beliefs based on their own learning. Continue to explore suitable for their own learning methods, make full use of the existing knowledge base, to maximize their potential. Of course, the key to this structure of learning is that teachers build a variety of self-learning platforms for students by organizing extra-curricular learning groups and creating online learning environments. Many students in the learning process design process easy to produce fear, the main reason is that as the learning content continues to deepen, in the process of extra-curricular learning, programming and debugging problems encountered in the often can not be solved in time, and their own And lack of self-learning ability. Teachers can practice in extracurricular study, the students every 3 to 5 people form a group. The principle of grouping is intra-group heterogeneity, and the homogeneity among groups. Each team member cooperates with each other in practice to form a "working team". The team leader is responsible for organizing the course study and practical discussion of the team members. In this collaborative learning, students 'various learning problems can be discussed and digested in time, meanwhile, they can influence each other in solving problems, ways of thinking and learning experiences, and can well promote the cultivation of students' autonomous learning ability , Improve learning interest. 


\section{Build Self-learning Network Platform}

The key to cultivating autonomous learning mode lies in establishing a good evaluation platform for students' extracurricular learning. Using the network platform, teachers can change the confusion over the unmonitored students' extra-curricular learning in the past and fully participate in and manage their learning process. The web platform also provides rich resources for students' self-study and review, including curriculum syllabus, teaching El calendar, online courseware, teaching videos, course design, reference materials, and personalized assistance.

We use Courses online teaching platform to broaden the teaching space in $\mathrm{C}$ programming teaching. The online online teaching platform includes modules such as course forum, course notification, teaching documents, teaching resources, coursework, online evaluation, plagiarism detection and code examples. This online teaching platform for different users, set up a different personalized space, including administrator space, teacher space and student space. Administrator space for administrators to provide a rich, practical teaching management capabilities. Teacher space provides teachers with a strong online preparation and teaching environment, full of interactive modules, which greatly broadened the teaching space. Student space provides students with a strong environment for personalized learning and research learning. Using "online teaching platform", teachers can create rich learning situations for students and ask questions to students. Arrange and modify assignments according to individual teaching schedule and supervise the completion of assignments. Students can be motivated to present their learning goals through the platform Learning motivation. Teachers can also use the plagiarism detection system to detect students submit the source plagiarism phenomenon exists. Students can use the platform for autonomous learning and use of the platform for reflection and summary. This real-time and non-real-time channel established between teachers and students effectively improves teaching effectiveness.

\section{Changes in Assessment Methods, Increase the Test Machine, Multiple Assessment}

How to evaluate the learning effect of students is a baton for students to learn. C language programming course teaching purpose is to develop students proficiency in the use of computer language programming and debugging procedures to solve practical problems. The shortcomings of the traditional written test form is obvious, only through the operation of the machine can simultaneously assess the ability to prepare and debug the program. On the plane to assess the actual programming ability, can well supervise the students in the usual learning focus on debugging procedures.

C language learning needs to learn step by step, so the evaluation of academic performance to encourage each stage of learning content-based learning. To this end we will test the pressure decomposition to each stage of learning, machine test stage by stage, to complete 3 tests. The final examination method to test-based performance, accounting for about 50\%, written examination results accounted for $20 \%$, usually $30 \%$. Usually on the plane test scores transparent, so that students usually remain nervous and conscientiously completed each stage of learning. In this learning process, students can see their own stage results every time, learning enthusiasm can get the maximum encouragement. With the promotion of such assessment forms, students 'ability to program and debug programs has generally been greatly improved, playing a role as a baton and effectively enhancing students' interest in learning and programming skills.

\section{References}

[1] H.G. "C language programming" teaching reform mouth]. Computer Knowledge and Technology, 2006 (8): 175-176.

[2] M.H.W. M.W. "C programming" teaching innovation ability to develop EJ]. Science and Technology Information, 2008 (35): 86-88. 
[3] J.B.X. "C language programming teaching problems and reform proposals" [J]. Journal of Chongqing University of Posts and Telecommunications: Social Sciences Edition, 2008 (2); 137-140.

[4] Y.H.T Gong An. Program Design Language Experiment Teaching Discussion]. Journal of Electrical and Electronic Education, 2006 (3): 86-94.

[5] L.C. In $\mathrm{C}$ language teaching to inspire and train students in programming thinking [J]. Fujian Computer, 2006 (12): 207-208.

[6] The first Wyeth. German teacher training guide [M]. Yuan Yi An, translation. Beijing: People's Education Press, 2001.

[7] Q.L.Y. Project Teaching Method "in the computer language programming course teaching practice and exploration [J]. Anhui Metallurgical Technology Vocational College, 2009 (19): 69-72.

[8] N.Z. Research on the Construction of College Students' Autonomous Learning Environment Based on Internet [D]. Nanjing: School of Humanities and Social Sciences, Nanjing University of Aeronautics and Astronautics, 2015. 